\title{
CORRECTION
}

\section{Correction to: Practical framework for data-driven RANS modeling with data augmentation}

\author{
Xianwen Guo ${ }^{1} \cdot$ Zhenhua Xia $^{2}$ - Shiyi Chen ${ }^{1,3}$
}

Published online: 25 February 2022

(C) The Chinese Society of Theoretical and Applied Mechanics and Springer-Verlag GmbH Germany, part of Springer Nature 2022

\section{Correction to:}

Acta Mechanica Sinica (2021) 37(12):1750-1758

https://doi.org/10.1007/s10409-021-01147-2

In the original publication, the last equation in Eq. (8) should be

$T_{i j}^{2}=s_{i k} \omega_{k j}-\omega_{i k} s_{k j}$

Furthermore, Figs. 8-10 have been displayed in wrong orders. The correct orders of Figs. 8, 9, 10 are as follows:

The original article can be found online at https://doi.org/10.1007/ s10409-021-01147-2.

Zhenhua Xia

xiazh@zju.edu.cn

1 State Key Laboratory for Turbulence and Complex Systems, College of Engineering, Peking University, Beijing 100871, China

2 Department of Engineering Mechanics, Zhejiang University, Hangzhou 310027, China

3 Department of Mechanics and Aerospace Engineering, Southern University of Science and Technology, Shenzhen 518055, China 


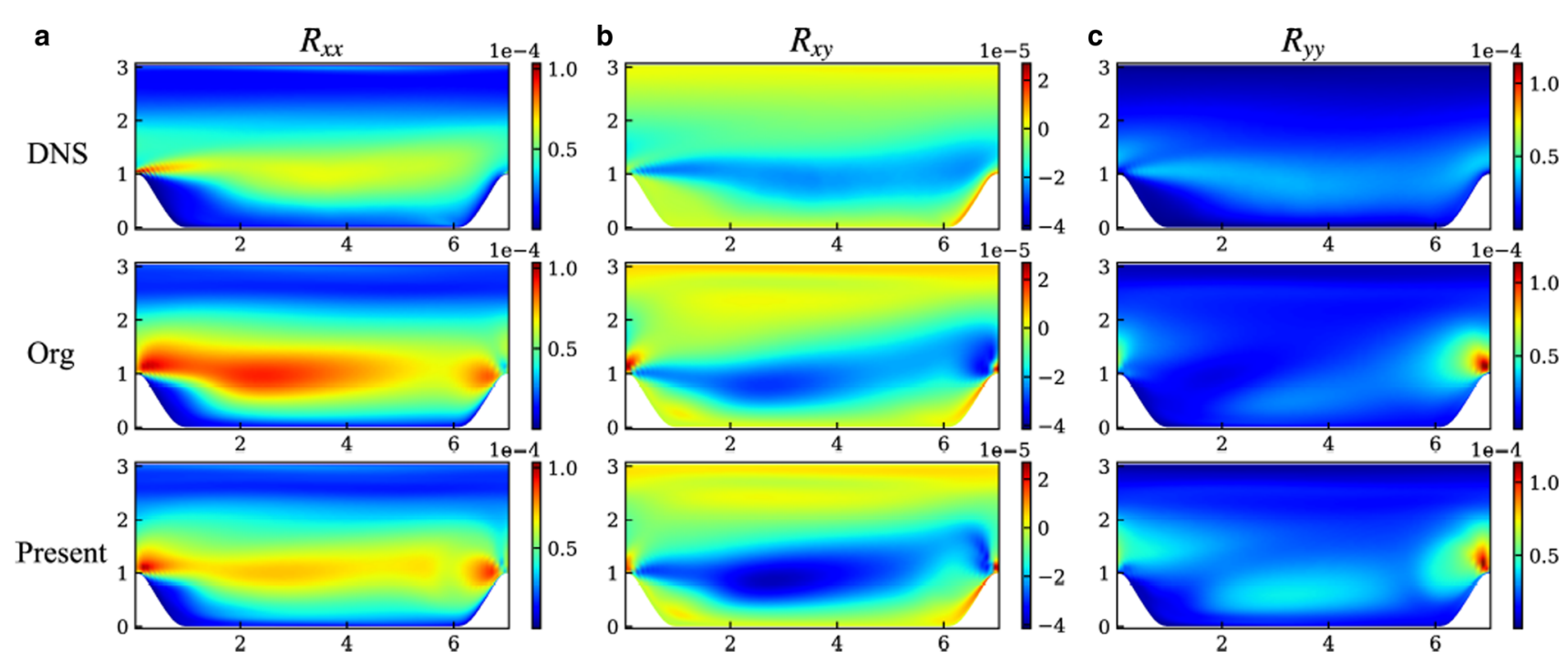

Fig. 8 Comparison of predicted Reynolds stress components for test case $\alpha=0.5$ between a DNS data; $\mathbf{b}$ Org; $\mathbf{c}$ Present model

$$
\text { a }
$$
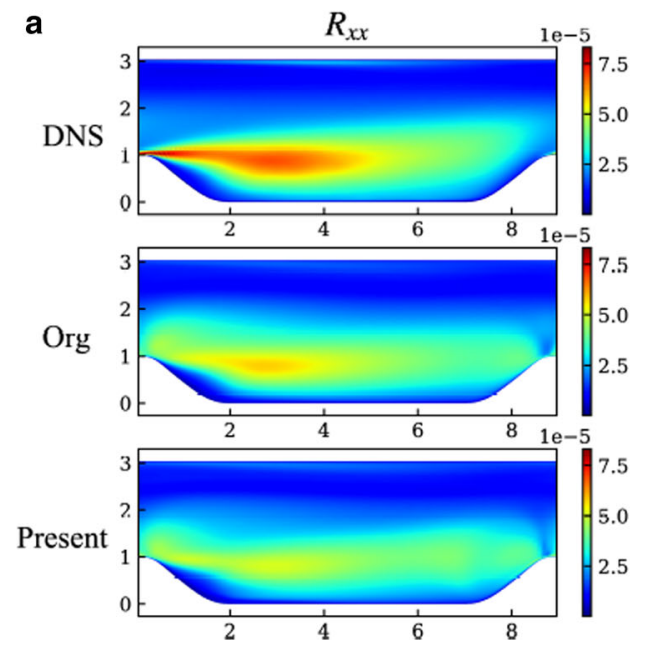
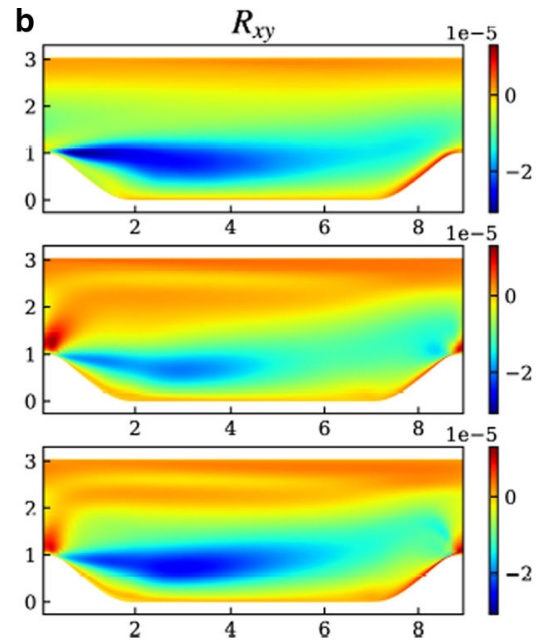
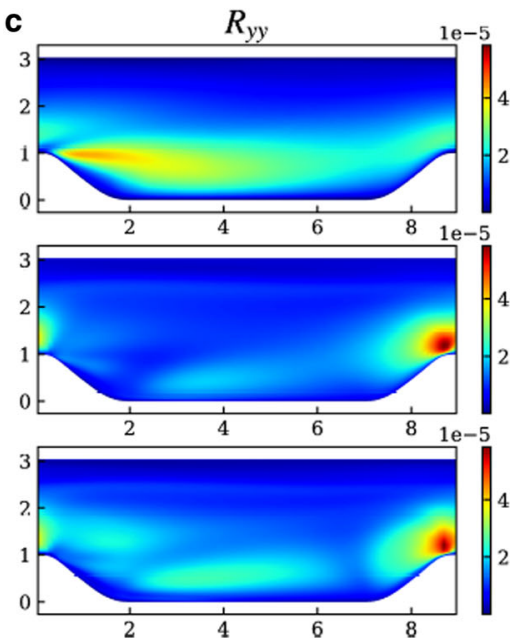

Fig. 9 Comparison of predicted Reynolds stress components for test case $\alpha=1.0$ between a DNS data; $\mathbf{b}$ Org; $\mathbf{c}$ Present model 

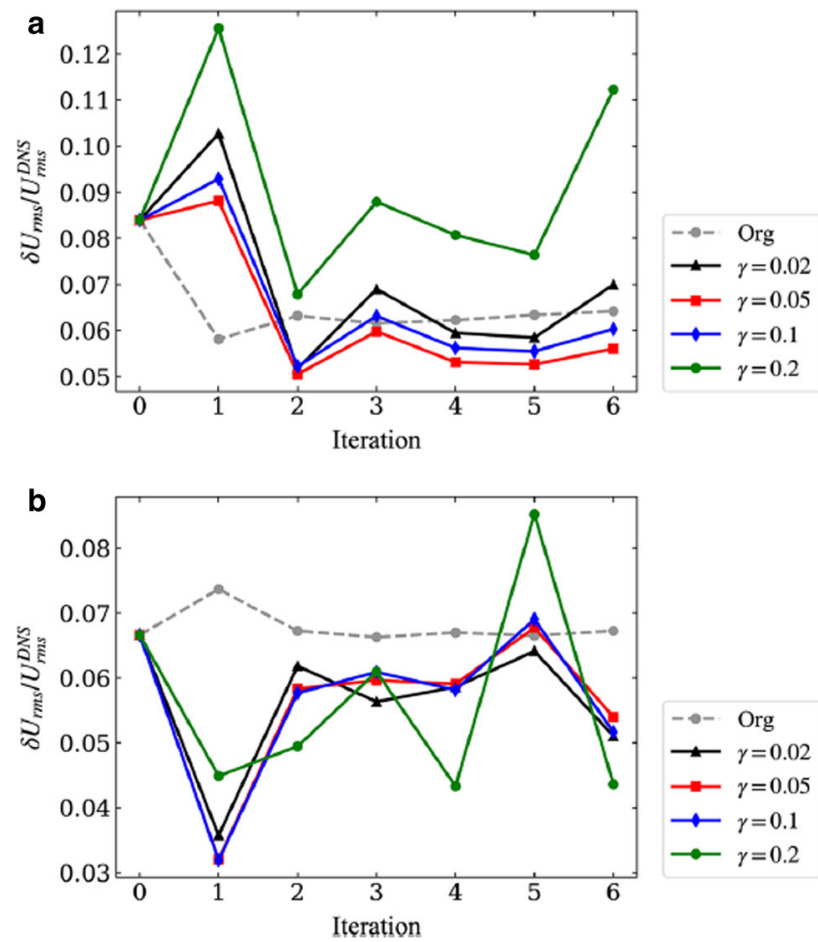

Fig. 10 Propagation error of velocity against iteration steps for $\mathbf{a}$ : test case $\alpha=0.5$; $\mathbf{b}$ : test case $\alpha=1.0$

Publisher's Note Springer Nature remains neutral with regard to jurisdictional claims in published maps and institutional affiliations. 